\title{
A Novel Method for Achieving Gradient Microstructure in a Cu-Al Alloy: Surface Spinning Strengthening (3S)
}

\author{
Chuan-Xi Ren ${ }^{1,2} \cdot$ Qiang Wang $^{1} \cdot$ Zhen-Jun Zhang $^{1} \cdot$ Yan-Kun Zhu ${ }^{1} \cdot$ Zhe-Feng Zhang $^{1,2}$
}

Received: 8 November 2016/Revised: 27 December 2016/Published online: 16 February 2017

(C) The Chinese Society for Metals and Springer-Verlag Berlin Heidelberg 2017

\begin{abstract}
A new designed surface strengthening method, surface spinning strengthening (3S), was applied to achieve gradient microstructure in the surface layer of a $\mathrm{Cu}-11$ at.\% $\mathrm{Al}$ alloy. According to the level of grain refinement, the gradient microstructure can be divided into four zones, including nanoscale grain zone, ultra-fine grain zone, fine grain zone and coarse grain zone from the surface to the matrix. Meanwhile, a plenty of grain boundaries and twin boundaries were introduced to inhibit the dislocation motion in the surface layer during the plastic deformation process. Consequently, the hardened layer with a microhardness gradient and high residual compressive stress was produced on the samples, and the yield strength of the $\mathrm{Cu}-11$ at.\% $\mathrm{Al}$ alloy was effectively improved after $3 \mathrm{~S}$ processing due to the strengthening effect caused by the gradient microstructure.
\end{abstract}

\section{KEY WORDS: Cu-Al alloy; Surface spinning strengthening (3S); Strength; Microhardness; Gradient} microstructure

\section{Introduction}

Fatigue fracture is the most common failure mode for the metallic components bearing the cyclic loading [1]. As is well known that the fatigue crack commonly nucleates at the surface of the metallic components [2], the hardened layer on the metals produced by surface strengthening can effectively restrict the initiation of the fatigue crack, which attracts wide attention in the past years [3, 4]. As the

Available online at http://link.springer.com/journal/40195

Qiang Wang

gmwang@imr.ac.cn

$₫$ Zhe-Feng Zhang

zhfzhang@imr.ac.cn

1 Shenyang National Laboratory for Materials Science, Institute of Metal Research, Chinese Academy of Sciences, Shenyang 110016, China

2 School of Materials Science and Engineering, University of Science and Technology of China, Hefei 230026, China methods of surface strengthening, mechanical surface strengthening processes are widely used to restrict the initiation of fatigue cracks. The strengthening effect derived from the mechanical surface strengthening processes can be mainly attributed to two aspects: the evolution of the microstructure and the introduction of the high residual compressive stress [5, 6]. However, only a few of those methods can cause both microstructural evolution and residual compressive stress in the surface layer of the metallic components.

The evolution of the microstructure in the surface layer of the metallic components, including grain refinement, deformation twinning and dislocation evolution, can effectively improve the surface strength by inhibiting the dislocation movement. For example, surface grinding and surface mechanical grinding treatment (SMGT) are representative methods which can reconstruct the microstructure in the surface layer of metals [7]. Usually, the reconstruction of the microstructure can cause the improvement in the mechanical properties in the surface layer. In this case, the strengthening effect may mainly attribute to the 
introduction of the gradient microstructure in the surface layer. In particular, the nanoscale grains at the topmost surface layer and micrometer-sized coarse grains in the matrix with a transition region between them can be obtained after the treatment. The previous studies have demonstrated that the materials with the gradient nanostructure can effectively extend the fatigue life of metallic materials $[5,8]$. Therefore, the evolution of microstructure induced by surface mechanical processing is an effective approach to improve some mechanical properties of the metallic components.

The residual compressive stress can decrease the stress at local area when the component suffers an applied stress and can also restrict the initiation of fatigue cracks $[9,10]$. Now according to the theory of surface plastic deformation, the residual compressive stress can be introduced into the surface layer [6]. Among the strengthening methods, shot peening (SP) is a widely accepted surface strengthening method which was developed at the beginning of the last century $[9,11]$. Many literatures reported that the residual compressive stress introduced by SP can significantly increase the fatigue life of the metallic components [12]. Some other methods, such as surface rolling strengthening (SRT) [4, 13], surface mechanical attrition treatment (SMAT) [14] and surface mechanical rolling treatment (SMRT) [15], can also create residual compressive stress in the surface layer of the components. Overall, the residual compressive stress may be accepted as a method that can effectively decrease the stress level in the surface layer of the component when it suffers an applied stress in service.

In recent years, some important methods have been developed to prepare high-performance materials by severe plastic deformation (SPD) [16, 17]. However, the surface strengthening methods based on the SPD caused by shear stress need to get more attention and research. In this study, a new method, surface spinning strengthening (3S) (see Fig. 1a), was designed for the purpose of obtaining gradient microstructure in the surface layer due to the surface severe plastic deformation on the plane-type metallic components and the introduction of the residual compressive stress at the same time. The characteristics of $3 \mathrm{~S}$ are summarized as follows.

1. During the $3 \mathrm{~S}$ processing, a special machining tool controlled by a milling machine is perpendicular to the metallic component and moves along the processing direction, and the rapid rotation of the machining tool can generate an extremely high shear stress and compressive stress.

2. The shear stress forces the flow of the surface metal layer resulting in the evolution of the microstructure, introducing the residual compressive stress in the surface layer of the metal to some extent.

3. The $3 \mathrm{~S}$ is a novel method strengthening the surface for metallic materials, especially for plane-type metallic components. By reconstructing the surface microstructure, the components will have some improved properties, like wear resistance and fatigue life. In this study, we will investigate the strengthening effect of the $3 \mathrm{~S}$ method and provide a better understanding on the surface strengthening mechanism of the metallic component.

\section{Experimental}

$\mathrm{Cu}-11$ at.\% $\mathrm{Al}$ alloy (abbreviated as $\mathrm{Cu}-11 \mathrm{Al}$ alloy) was chosen as the target material in this study, and the alloy rod was processed into the billets by wire electrical discharge

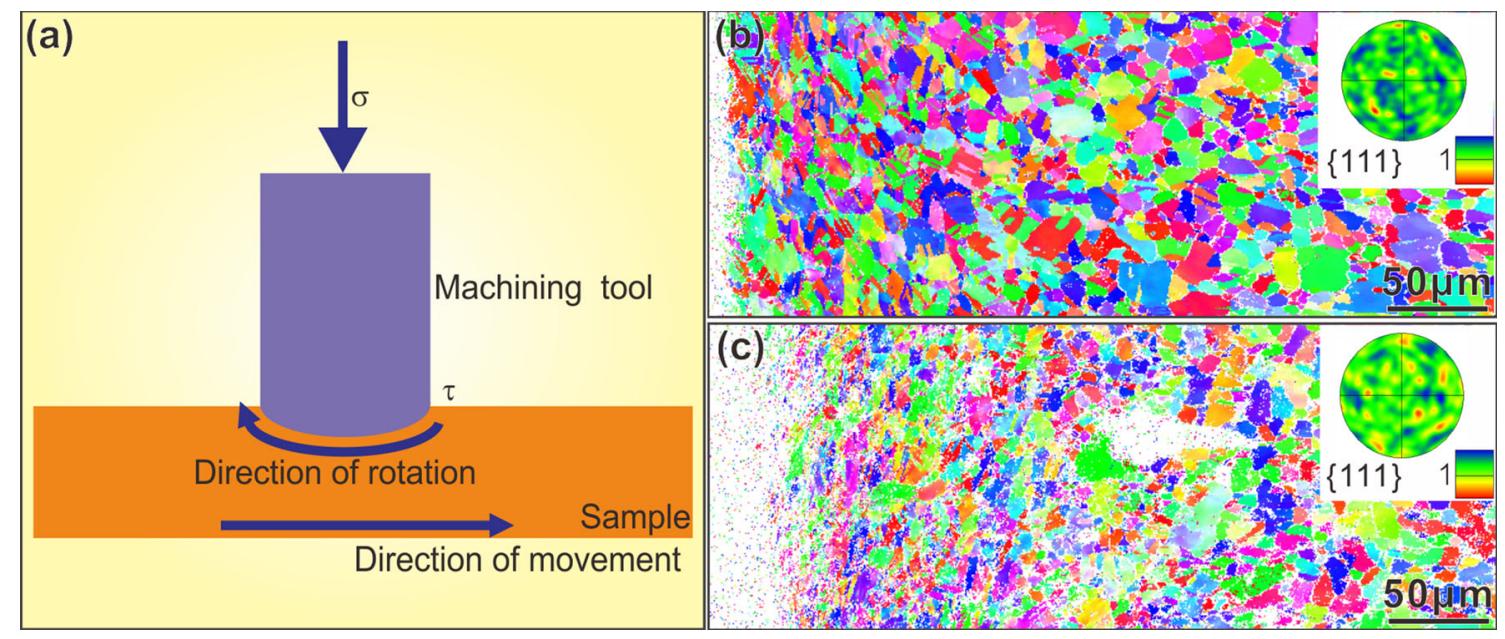

Fig. 1 a Schematic illustration of the surface spinning strengthening (3S) setup. 3S-induced gradient microstructures in the surface layer of $\mathrm{Cu}-$ $11 \mathrm{Al}-200$ sample $\mathbf{b}$ and $\mathrm{Cu}-11 \mathrm{Al}-400$ sample $\mathbf{c}$, including the orientation distribution maps and the pole figures 
machining (WEDM) with a surface area of $16 \mathrm{~mm} \times 16 \mathrm{~mm}$ for the following $3 \mathrm{~S}$ processing. The sample surface was ground to $1500 \# \mathrm{SiC}$ abrasive paper, cleaned with anhydrous ethanol and dried in cold blowing air. Then, the samples were processed with various feed amounts (defined as the displacement of the machining tool moving in the direction perpendicular to the surface of the sample) at the same machining rate, and meanwhile, the sample surface was cooled by a liquid coolant. The samples processed with the feed amounts of 200 and $400 \mu \mathrm{m}$ were named as $\mathrm{Cu}-11 \mathrm{Al}-200$ and $\mathrm{Cu}-11 \mathrm{Al}-400$, and $\mathrm{Cu}-11 \mathrm{Al}-0$ without the $3 \mathrm{~S}$ processing, respectively. Tensile tests were carried out on an Instron 5982 testing machine with a strain rate of $1 \times 10^{-3} \mathrm{~s}^{-1}$. Moreover, the microhardness was tested by an AMH43 full automatic microhardness tester fitted with a Vickers indenter, with a load of $100 \mathrm{~g}$ and $\mathrm{a}$ holding time of $13 \mathrm{~s}$. The residual stress was measured by Proto LXRD X-ray stress analyzer. The samples for transmission electron microscopy (TEM) were ground to a thickness of $\sim 0.05 \mathrm{~mm}$ and then twin-jet-electropolished at 4-8 ${ }^{\circ} \mathrm{C}$ using a solution of $\mathrm{H}_{3} \mathrm{PO}_{4}: \mathrm{C}_{2} \mathrm{H}_{5} \mathrm{OH}: \mathrm{H}_{2} \mathrm{O}=1: 1: 2$ (vol.). The samples for electron backscattering diffraction (EBSD) were polished using 2000\# SiC abrasive paper and then electrolytic polished at room temperature for $\sim 60 \mathrm{~s}$ using the same solution as the TEM samples. The gradient microstructure of $\mathrm{Cu}-11 \mathrm{Al}$ alloy was characterized by FEI Tecnai F20 (TEM) and LEO SUPRA 35 field emission scanning electron microscopy (SEM).

\section{Results and Discussion}

After the $3 \mathrm{~S}$ processing, the orientation image maps and pole figures in the surface layers of the $\mathrm{Cu}-11 \mathrm{Al}-200$ and $\mathrm{Cu}-11 \mathrm{Al}-400$ samples are shown in Fig. 1b, c, respectively. The orientation image maps show that the orientation of the grains in the surface layer distributed randomly, and the samples have little deformation texture based on the pole figures. It is clear that the microstructure in the topmost several hundreds of micrometers from the surface to the matrix along the normal direction exhibits a gradient characteristic. As for the SMAT method, the gradient microstructure in the surface layer is constituted of nanostructured layer, fined-grained layer, deformed coarsegrained layer and strain-free coarse-grained matrix layer, owing to the distribution of the gradient strain along the depth [18, 19]. Compared to this division of the gradient microstructure based on grain size and deformation process, we chose an easier approach to understand the change of the grains in the hardened layer.

Based on the observations, the microstructure in the surface layer in the $3 \mathrm{~S}$ processing can be divided into four zones according to the dimensions of the grains of the two samples. Taking $\mathrm{Cu}-11 \mathrm{Al}-400$ as a sample, there is about 50 - $\mu \mathrm{m}$-thick zone where the sizes of most grains are below $100 \mathrm{~nm}$. It means that the deformation in this zone is very severe, which is named as nanoscale grain (NSG) zone. For the pure $\mathrm{Cu}$ processed by SMAT, a nanostructured surface layer of about $35 \mu \mathrm{m}$ thick was formed [18]. The zone from $\sim 50$ to $\sim 100 \mu \mathrm{m}$ is named as ultra-fine grain (UFG) zone where the grains are refined from several hundreds of nanometers to one micrometer. In the next zone between the matrix and the UFG zone, the grains are refined to several micrometers, which is named as fine grain (FG) zone. The last zone is coarse grain (CG) zone in the matrix. The above four zones constitute the gradient microstructure of the $\mathrm{Cu}-11 \mathrm{Al}$ alloy processed by $3 \mathrm{~S}$ method.

Figure 2 presents the typical bright-field TEM micrographs of the FG zone for $\mathrm{Cu}-11 \mathrm{Al}-200$ (Fig. 2a) and $\mathrm{Cu}-$ 11Al-400 (Fig. 2b) samples after $3 \mathrm{~S}$ processing. It is well known that slip and twinning are two plastic deformation modes in the face-centered cubic (fcc) metals and alloys [20, 21]. Commonly, the $\mathrm{Cu}-11 \mathrm{Al}$ alloy has lower stacking fault energy (SFE) than the pure $\mathrm{Cu}$, and twinning is one of the major deformation modes, so it is easier to introduce deformation twins during the 3S processing [22-24]. Abundant deformation twins appear, and twin bands intersect with each other in the FG zone in the surface layer of the $\mathrm{Cu}-11 \mathrm{Al}$ alloy after the $3 \mathrm{~S}$ processing. As shown in Fig. 2c, $\mathrm{d}$, the grains are refined to a dimension of dozens of nanometers, about $50-100 \mathrm{~nm}$ or even less. Hence, the $3 \mathrm{~S}$ processing is a novel method for surface nanocrystallization.

As shown in Fig. 3a, the average microhardness of the $\mathrm{Cu}-11 \mathrm{Al}-0$ sample is $\sim 136.1 \mathrm{HV}$. After the $3 \mathrm{~S}$ processing, the microhardness in the surface layer of the $\mathrm{Cu}-11 \mathrm{Al}-200$ sample is enhanced significantly, and the maximum value of the microhardness is about $238.2 \mathrm{HV}$, that is to say, the microhardness increases by about $75.0 \%$ in the topmost surface layer. Similarly, the maximum value of the microhardness in the topmost surface layer of $\mathrm{Cu}-11 \mathrm{Al}$ 400 sample is about $247.6 \mathrm{HV}$, which is a little bit higher than that of $\mathrm{Cu}-11 \mathrm{Al}-200$ sample. The microhardness curves of $\mathrm{Cu}-11 \mathrm{Al}-200$ and $\mathrm{Cu}-11 \mathrm{Al}-400$ samples change gradually, and they can be expressed an equation with the depth, $d$, as follows:

$H v=H v^{\mathrm{m}}+\Delta H v \cdot e^{R d}$,

where $H v$ is the microhardness at some point in the surface layer of the sample, $H v^{\mathrm{m}}$ is the value of the microhardness in the matrix, $d$ is the distance of the point to the surface, $R$ is the hardening exponent, and $\Delta H v$ is the maximum increment in the microhardness, as follows:

$\Delta H v=H v^{\mathrm{M}}-H v^{\mathrm{m}}$,

where $H v^{\mathrm{M}}$ is the maximum value of the microhardness in the surface layer. 

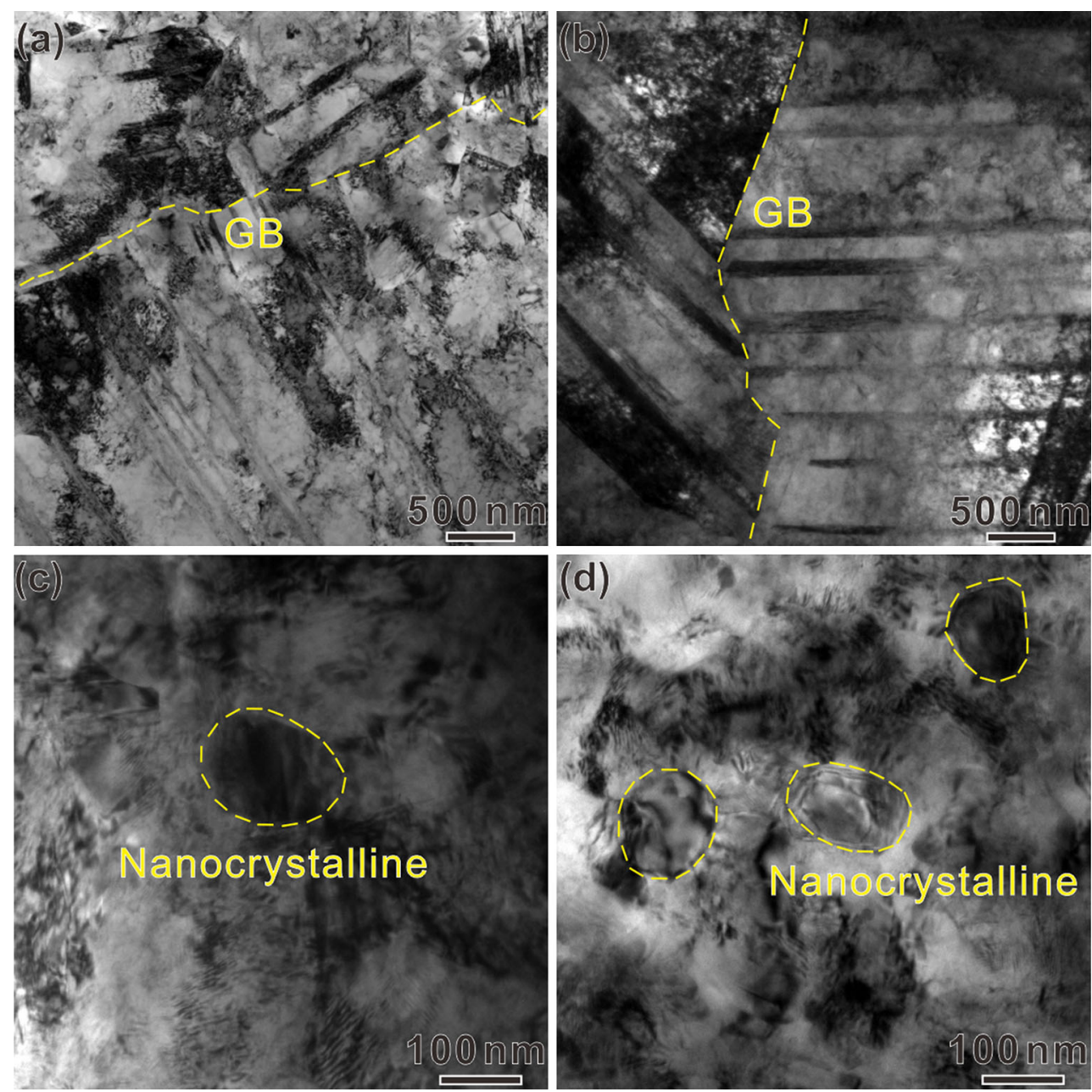

Fig. 2 TEM micrographs of $\mathrm{Cu}-11 \mathrm{Al}$ alloy: a $\mathrm{Cu}-11 \mathrm{Al}-200$ sample in the fine grain zone, $\mathbf{b} \mathrm{Cu}-11 \mathrm{Al}-400$ sample in the fine grain zone, $\mathbf{c} \mathrm{Cu}-$ $11 \mathrm{Al}-200$ sample in the nanoscale grain zone, $\mathbf{d ~ C u}-11 \mathrm{Al}-400$ sample in the nanoscale grain zone

(a)

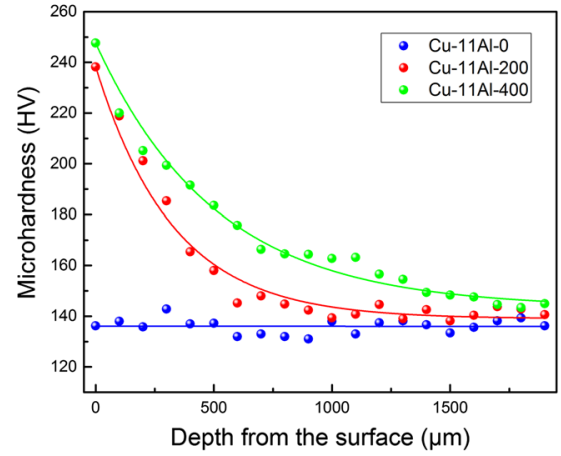

(b)

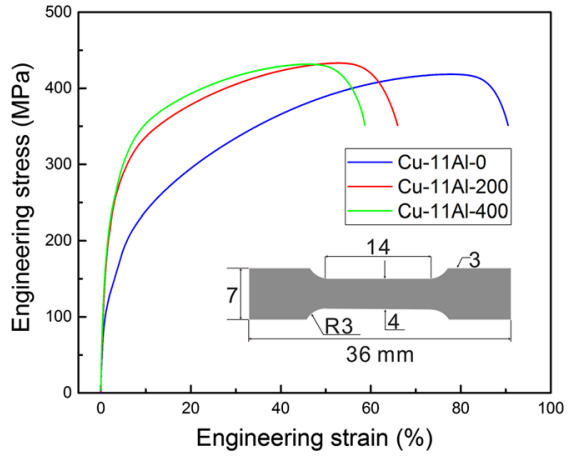

(c)

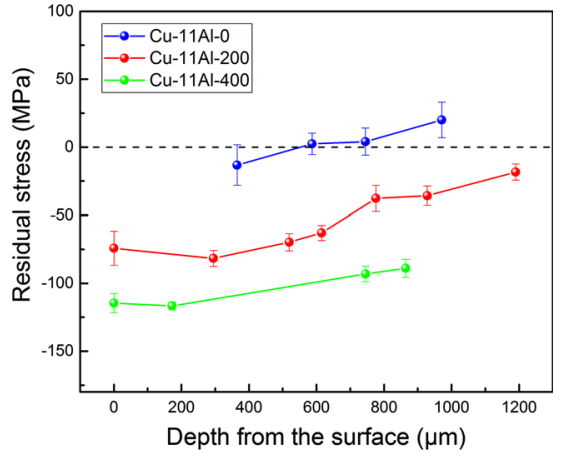

Fig. 3 a Variation of the gradient mechanical property of $\mathrm{Cu}-11 \mathrm{Al}$ alloy with the depth from the surface, $\mathbf{b}$ tensile engineering stress-strain curves of $\mathrm{Cu}-11 \mathrm{Al}$ alloy with different $3 \mathrm{~S}$ processing feed amounts, $\mathbf{c}$ residual stress profiles following different $3 \mathrm{~S}$ processing depths on $\mathrm{Cu}-$ $11 \mathrm{Al}$ alloy

In the $3 \mathrm{~S}$ processing, $H v^{\mathrm{M}}$ is the maximum microhardness achieved by the $3 \mathrm{~S}$ processing and also strongly depends on the nature of materials. $\Delta H v$ is related to the $3 \mathrm{~S}$ feed amount. By controlling the different $3 \mathrm{~S}$ feed amounts, different $\Delta H v$ of hardened layer can be achieved. For $\mathrm{Cu}-$ $11 \mathrm{Al}$ alloy, $\Delta H v$ is $102.1 \mathrm{HV}$, and $R$ is -0.0028 in $\mathrm{Cu}-$ $11 \mathrm{Al}-200$ sample, while $\Delta H v$ is $111.5 \mathrm{HV}$, and $R$ is -0.0016 in $\mathrm{Cu}-11 \mathrm{Al}-400$ sample. Generally, the hardened 
layer can be defined as the zone in which the microhardness is significantly different from the matrix [25]. When the microhardness in the hardened layer decreases to $H v^{\mathrm{m}}+10(\mathrm{HV})$, there is little effect on the strengthening, and the thickness of the hardened layer is defined by this depth from the surface when the microhardness value is $H v^{\mathrm{m}}+10(\mathrm{HV})$. For the $\mathrm{Cu}-11 \mathrm{Al}-200$ sample, the $3 \mathrm{~S}$ processing can create a hardened layer with the thickness of about $830 \mu \mathrm{m}$; however, for the $\mathrm{Cu}-11 \mathrm{Al}-400$ sample, the thickness of the hardened layer achieves about $1507 \mu \mathrm{m}$, which is significantly thicker than that of the $\mathrm{Cu}-$ 11Al-200 sample.

The thickness of the hardened layer is also different depending on the processing method and the categories of materials. For example, the AISI 316L stainless steel processed by SMRT has a depth of $\sim 1 \mathrm{~mm}$ with a gradient nanostructured surface layer [5]. For ultrasonic surface rolling process (USPP), the hardness at the top surface increases from the initial state to $385 \mathrm{HV}$, and the hardened layer thickness is about $300 \mu \mathrm{m}$ in Ti-6Al-4V [10]. Additionally, the decreasing rate of the microhardness in the surface layer of $\mathrm{Cu}-11 \mathrm{Al}-400$ sample is obviously slower than that of $\mathrm{Cu}-11 \mathrm{Al}-200$ sample. Therefore, the value of $R$ represents the decreasing tendency of the microhardness from the surface to matrix in the hardened layer. $R$ of $\mathrm{Cu}-11 \mathrm{Al}-400$ sample is larger, and this result indicates that the strengthening effect may be improved with the increase in the feed amount of $3 \mathrm{~S}$ processing.

In addition to the hardness, the yield strength of $\mathrm{Cu}-$ $11 \mathrm{Al}$ alloy can also be improved by surface strengthening on the basis of the tensile stress-strain curves as shown in Fig. 3b. For the $\mathrm{Cu}-11 \mathrm{Al}-200$ sample, the yield strength increases from $\sim 80 \mathrm{MPa}(\mathrm{Cu}-11 \mathrm{Al}-0)$ to $\sim 140 \mathrm{MPa}$, while for the $\mathrm{Cu}-11 \mathrm{Al}-400$ sample, the yield strength increases to $\sim 160 \mathrm{MPa}$. Commonly, the strength and ductility are mutually exclusive in metallic materials, and elongation to failure is a measure of the material ductility $[17,26]$. With increasing $3 \mathrm{~S}$ feed amount, the elongation of $\mathrm{Cu}-11 \mathrm{Al}-200$ sample decreases from $\sim 80$ to $\sim 55 \%$ and the elongation of $\mathrm{Cu}-11 \mathrm{Al}-400$ sample decreases to $\sim 45 \%$. For ultimate tensile strength, it is about $420 \mathrm{MPa}$ $(\mathrm{Cu}-11 \mathrm{Al}-0), 433 \mathrm{MPa}(\mathrm{Cu}-11 \mathrm{Al}-200)$ and $431 \mathrm{MPa}(\mathrm{Cu}-$ $11 \mathrm{Al}-400)$, respectively. It seems that the $3 \mathrm{~S}$ processing only influences a little on the ultimate tensile strength of $\mathrm{Cu}-11 \mathrm{Al}$ alloy. The major reason for the improvement in yield strength is that the surface microstructure in the hardened layer was modified by the $3 \mathrm{~S}$ processing. The $\mathrm{Cu}-11 \mathrm{Al}-400$ sample has a higher increase in the yield strength due to the thicker hardened layer. Different from $\mathrm{Cu}-\mathrm{Al}$ alloys, the texture in the hardened layer is also important to the yield strength for some other materials [27]. In the $3 \mathrm{~S}$ processing, the improvement in yield strength can be regarded as the grain refinement strengthening and strain strengthening in the surfacehardened layer, and this is a result of hindering the dislocation motion [28].

Besides the microstructure evolution, the residual stress is also widely accepted as a parameter to evaluate the effect of the surface strengthening $[29,30]$. The residual stress of $\mathrm{Cu}-11 \mathrm{Al}$ alloy with the $3 \mathrm{~S}$ treatment was also measured, and the results are shown in Fig. 3c. With increasing $3 \mathrm{~S}$ feed amount from 200 to $400 \mu \mathrm{m}$, the maximum residual compressive stress increases from $-74.20(\mathrm{Cu}-11 \mathrm{Al}-200)$ to $-114.56 \mathrm{MPa}(\mathrm{Cu}-11 \mathrm{Al}-400)$. From NSG to CG zone, the residual compressive stress decreases constantly in $\mathrm{Cu}-$ $11 \mathrm{Al}-200$ and $\mathrm{Cu}-11 \mathrm{Al}-400$ samples. The residual stress is commonly caused by the plastic incompatibility stress, intergranular stress, and so on during the plastic deformation [6, 8, 29]. Undoubtedly, $\mathrm{Cu}-11 \mathrm{Al}-400$ sample obtains the highest residual compressive stress in the surface layer, and $\mathrm{Cu}-11 \mathrm{Al}-400$ sample experienced severer plastic deformation during the $3 \mathrm{~S}$ process.

Furthermore, the relation between the microhardness and the gradient microstructure in the hardened layer is schematically shown in Fig. 4. In the NSG zone, the grains are refined to nanoscale grains induced by the very severe plastic deformation. The grains in the UFG zone are also refined, but the level of the refinement is in between the NSG zone and the FG zone. In addition, abundant twins were induced into the refined grains. It was reported that those GBs and TBs can impede the movement of dislocations in the UFG zone [31, 32]. With the cooperation of TBs and GBs, the dislocation motion is also limited in the FG zone. Meanwhile, there are plenty of dislocations, GBs and deformation twins, increasing the flow stress of

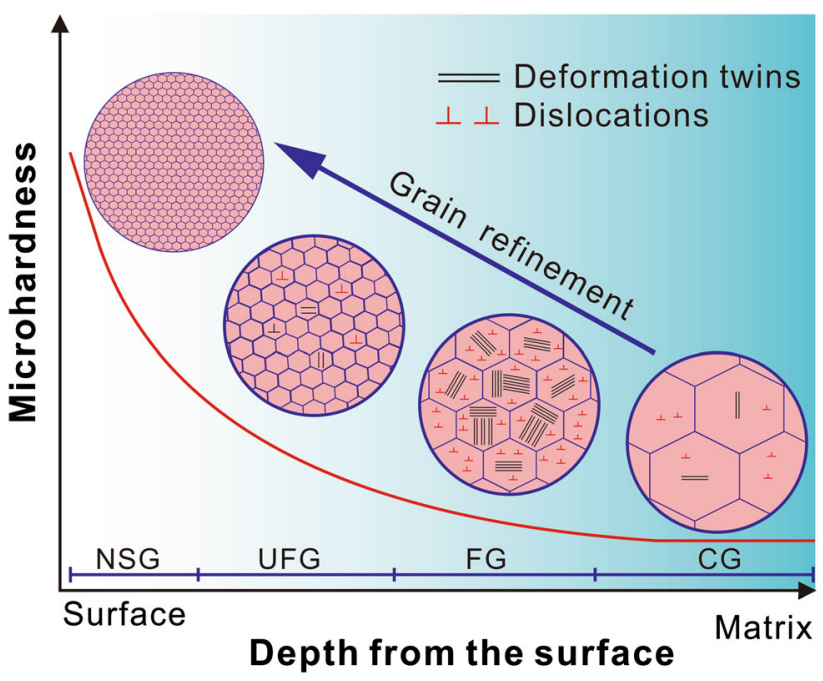

Fig. 4 Schematic illustration of the variation of the microhardness with the depth from the surface, and the gradient microstructure with grain refinement in the surface layer of $\mathrm{Cu}-11 \mathrm{Al}$ alloy processed by the $3 \mathrm{~S}$ method 
dislocations [33, 34]. Therefore, the surface layer of the $\mathrm{Cu}-11 \mathrm{Al}$ alloy was strengthened during the $3 \mathrm{~S}$ processing. From the CG zone to the NSG zone, the plastic deformation is weakened gradually along the normal direction, and the grains of $\mathrm{Cu}-11 \mathrm{Al}$ alloy are also refined gradually. For the microhardness in the hardened layer, the microhardness decreases gradually with increasing depth to the surface in an exponent type, and the microstructure also changes accordingly. The evolution of the microstructure results in the increase in the microhardness in the surface layer of $\mathrm{Cu}-11 \mathrm{Al}$ alloy, and a hardened layer is created on $\mathrm{Cu}-11 \mathrm{Al}$ alloy. In the hardened layer, the two major strengthening mechanisms are grain refinement strengthening and strain strengthening [35-37], and the grain refinement plays a dominant role in the strengthening of the NSG and UFG zone.

\section{Conclusion}

It is confirmed that $3 \mathrm{~S}$ is an effective method to enhance the yield strength and surface hardness, extend the hardened layer thickness, introduce the residual stress and obtain the gradient microstructure. The microstructure in the surface layer of $\mathrm{Cu}-11 \mathrm{Al}$ alloy changes gradually and exhibits a gradient characteristic. Furthermore, the gradient microstructure can be divided into four zones, including NSG zone, UGF zone, FG zone and CG zone, according to the level of the grain refinement. In addition, the yield strength of the $\mathrm{Cu}-11 \mathrm{Al}$ alloy treated by $3 \mathrm{~S}$ was significantly improved. The high residual compressive stress was introduced into the surface layer of $\mathrm{Cu}-11 \mathrm{Al}$ alloy. The microhardness in the hardened layer decreased gradually with the depth form the surface, and the thickness of the hardened layer increases markedly with increasing $3 \mathrm{~S}$ feed amount.

Acknowledgements This work was financially supported by the National Natural Science Foundation of China (NSFC) under Grant Nos. 51331007 and 51501198.

\section{References}

[1] E.P. Busso, S.D. Antolovich, Acta Mater. 107, 484 (2016)

[2] R.O. Ritchie, Int. J. Fract. 100, 55 (1999)
[3] A. Pineau, A. Amine Benzerga, T. Pardoen, Acta Mater. 107, 508 (2016)

[4] N. Tsuji, S. Tanaka, T. Takasugi, Mater. Sci. Eng. A 488, 139 (2008)

[5] H.W. Huang, Z.B. Wang, J. Lu, K. Lu, Acta Mater. 87, 150 (2015)

[6] P.J. Withers, Rep. Prog. Phys. 70, 2211 (2007)

[7] T.H. Fang, W.L. Li, N.R. Tao, K. Lu, Science 331, 1587 (2011)

[8] T. Roland, D. Retraint, K. Lu, J. Lu, Scr. Mater. 54, 1949 (2006)

[9] V. Llaneza, F.J. Belzunce, Appl. Surf. Sci. 356, 475 (2015)

[10] H.B. Wang, G.L. Song, G.Y. Tang, J. Alloys Compd. 681, 146 (2016)

[11] N. Tsuji, S. Tanaka, T. Takasugi, Surf. Coat. Technol. 203, 1400 (2009)

[12] M.A.S. Torres, H.J.C. Voorwald, Int. J. Fatigue 24, 877 (2002)

[13] C. Yuan, R.D. Fu, F.C. Zhang, X.Y. Zhang, F.C. Liu, Mater. Sci. Eng. A 565, 27 (2013)

[14] Y.M. Lin, J. Lu, L.P. Wang, T. Xu, Q.J. Xue, Acta Mater. 54, 5599 (2006)

[15] X.C. Liu, H.W. Zhang, K. Lu, Science 342, 337 (2013)

[16] K.S. Kumar, H. Van Swygenhoven, S. Suresh, Acta Mater. 51, 5743 (2003)

[17] R.Z. Valiev, Nat. Mater. 3, 511 (2004)

[18] K. Lu, J. Lu, Mater. Sci. Eng. A 375, 38 (2004)

[19] T. Roland, D. Retraint, K. Lu, J. Lu, Mater. Sci. Eng. A 445, 281 (2007)

[20] J. Hirsch, K. Lucke, M. Hatherly, Acta Metall. 36, 2905 (1988)

[21] J.W. Christian, S. Mahajan, Prog. Mater. Sci. 39, 1 (1995)

[22] X.H. An, Q.Y. Lin, S.D. Wu, Z.F. Zhang, R.B. Figueiredo, T.G. Langdon, Philos. Mag. 91, 3307 (2011)

[23] R. Liu, Z.J. Zhang, Z.F. Zhang, Mater. Sci. Eng. A 666, 123 (2016)

[24] X.H. An, Q.Y. Lin, S.D. Wu, Z.F. Zhang, R.B. Figueiredo, N. Gao, T.G. Langdon, Scr. Mater. 64, 954 (2011)

[25] C. Ye, A. Telang, A.S. Gill, S. Suslov, Y. Idell, K. Zweiacker, J.M.K. Wiezorek, Z. Zhou, D. Qian, S.R. Mannava, V.K. Vasudevan, Mater. Sci. Eng. A 613, 274 (2014)

[26] M.A. Meyers, A. Mishra, D.J. Benson, Prog. Mater Sci. 51, 427 (2006)

[27] G.Z. Voyiadjis, B. Deliktas, Int. J. Plast. 25, 1997 (2009)

[28] D. Kiener, A.M. Minor, Acta Mater. 59, 1328 (2011)

[29] F. Macionczyk, W. Bruckner, J. Appl. Phys. 86, 4922 (1999)

[30] A.H. Heuer, F. Ernst, H. Kahn, A. Avishai, G.M. Michal, D.J. Pitchure, R.E. Ricker, Scr. Mater. 56, 1067 (2007)

[31] K. Lu, L. Lu, S. Suresh, Science 324, 349 (2009)

[32] V. Yamakov, D. Wolf, S.R. Phillpot, A.K. Mukherjee, H. Gleiter, Nat. Mater. 1, 45 (2002)

[33] J. Wang, X. Zhang, MRS Bull. 41, 274 (2016)

[34] M.L. Kronberg, Acta Metall. 5, 507 (1957)

[35] N. Tsuji, Y. Saito, H. Utsunomiya, S. Tanigawa, Scr. Mater. 40, 795 (1999)

[36] Y.Z. Tian, J.J. Li, P. Zhang, S.D. Wu, Z.F. Zhang, M. Kawasaki, T.G. Langdon, Acta Mater. 60, 269 (2012)

[37] L. Bardella, A. Panteghini, J. Mech. Phys. Solids 78, 467 (2015) 